\title{
The neurobiological bases of obsessive-compulsive disorder and Tourette syndrome
}

\author{
Marcos T. Mercadante1, Maria C. Rosario-Campos ${ }^{2,3}$, \\ Lucas C. Quarantini ${ }^{3}$, Fabio P. Sato ${ }^{2}$
}

\begin{abstract}
Objective: To describe and discuss evidence-based articles on the neurobiology of obsessive-compulsive disorder and Tourette syndrome.

Sources of data: A review of the most relevant papers on the phenomenology, neuroanatomy, neuroimaging, genetic and immunological aspects of these two disorders was performed.

Summary of the findings: Ritualistic behaviors and repetitive thoughts have been extensively studied in the last years. The definitions of obsessive-compulsive disorder and Tourette syndrome emphasize the existence of a continuum of symptoms, with high prevalence in the general population. Neurobiological findings have implicated genetic and immunological factors in the etiology of these two disorders.

Conclusions: Advances in neuroscience triggered genetic and immunological research studies, allowing new perspectives on the treatment of obsessive-compulsive disorder and Tourette syndrome patients.

J Pediatr (Rio J). 2004;80(2 Suppl):S35-S44: Obsessive-compulsive disorder, Tourette syndrome, tic disorders, neuroscience.
\end{abstract}

\section{Introduction}

Ritualistic behaviors are common to the human experience. These behaviors allow individuals in the same group to establish complex communication with each other, which facilitates and standardizes their relationships. In fact, rituals express a neuronal organization that improves behaviors and that has been developed for the selection of species. To some extent, we use rituals to "relieve the brain system," for instance, when taking a shower, we always apply soap to a certain part of the body first and then to another part, etc, thus "opening" our mind to other thoughts. Or, when we get home and leave objects, such as wallet or documents, always in the same place. These schemes, routines or rituals rely upon certain brain circuits. Interestingly enough, some of these rituals co-occur with superstitions, showing the cognitive aspect of thoughts, which are no longer just a repetitive behavior.

1. Graduate Program in Development Disorders, Universidade Presbiteriana Mackenzie, São Paulo, SP, Brazil.

2. Psychiatry Institute, Hospital das Clínicas, School of Medicine, Universidade de São Paulo (USP), São Paulo, SP, Brazil.

3. Department of Neuropsychiatry, Universidade Federal da Bahia (UFB), Salvador, BA, Brazil.
Therefore, rituals and superstitions are considered a normal part of child development. For example, preschool children create rituals, especially of bedtime, mealtime, and bath time. These repetitive behaviors are more frequent between the ages of two and four years. ${ }^{1}$ In school-aged children, rituals involve games with strict and extensively discussed and negotiated rules, which frequently take longer than the game itself. At this age, children also start collecting different objects, which is a current version of storing rituals.

Superstitious behaviors may involve bad luck or good luck. Children aged between two and six years have superstitions that are filled with fantasy - a characteristic of pre-logical or magical thinking. After acquiring logical or concrete thinking, children tend to change their superstitious behaviors, channeling them towards aspects of their own performance.

In some individuals, these behaviors get out of control, and they begin to show repetitive behaviors without any functionality, which are detrimental to their adaptive capacity. These events are known as obsessivecompulsive disorders (OCD) and tic disorders (TD). It is 
essential that we know when children's behaviors are no longer adaptive and become dysfunctional and pathological, requiring treatment. Usually, ordinary rituals help individuals to establish a relationship with the surrounding environment and also help them to control anxiety in times of difficulties, often giving them pleasure.

The present study provides some data on OCD and its association with TD and Tourette syndrome (TS), highlighting the role of neurobiology in the pathophysiology of these disorders.

\section{Obsessive-compulsive disorders and tic disorders}

OCD (see diagnostic criteria in Table 1) is a chronic disease characterized by obsessions and/or compulsions. Studies suggest the existence of different subtypes and the hypothesis that OCD is a heterogeneous disorder. Among the possible subtypes, OCD related to tics or to TS has been widely studied (Table 2).

It is currently estimated that 2 to $3 \%$ of adolescents have $O C D,^{2}$ and that it is possibly less frequent among children. On the other hand, TS affects 1 in every 1,000 men and 1 in every 10,000 women. However, TD affects up to $20 \%$ of school-aged children, who experience transient tics at some time during their development.

OCD is more frequently observed among boys, in whom symptoms tend to occur early on. Among adolescents, there has been an increase in the incidence of OCD in girls, with a 1:1 male/female ratio (the same ratio observed in adults).

TD are more common among boys, with a 9:1 ratio, especially in younger ones. Following the same tendency of $O C D$, this difference seemingly decreases in adolescence, showing a 3:1 ratio (the same ratio observed in adults). Epidemiological studies suggest that $5 \%$ of OCD patients also have TS, and that $20 \%$ are associated with TD. ${ }^{3}$

\section{Clinical course}

The diagnosis of childhood-onset OCD is not always an easy task. Children often hide their symptoms, and it might take a long time before parents can detect the problem. Quite often, symptoms are only perceived when skin wounds or gum injuries appear as a result of cleaning rituals, when children spend a long time in the bathroom, when their school performance is poor, when they have difficulty in falling asleep, or when they take a long time to eat.

In addition to the secretive nature of OCD, children's cognitive immaturity prevents them from organizing their thoughts in a clear manner. Tics, however, are easily identified. Motor tics usually start first, and vocal tics tend to appear later, and as with motor tics, they are usually mistaken for symptoms of upper respiratory infection.

\section{Obsessive-compulsive symptoms}

Obsessions are recurrent and persistent thoughts, impulses, or images that are experienced as intrusive and that cause anxiety and/or distress to the patient, who tries to ignore them or neutralize them with some other thought or action. ${ }^{4}$ The nature and types of obsessions vary considerably, and may correspond to any of the mental functions, characterized by words, thoughts, fears, worries, memories, images, sounds, or scenes. Some of the obsessions most frequently reported by children include: fear of contamination [children feel anxious, worried or scared that germs, body secretions (urine, feces, saliva), environmental pollutants (radiation, dust), or simply that the contact with sticky or "disgusting" substances may be harmful to them or to someone in their family]; and aggressive thoughts and/or images [fear of harming themselves or others (sometimes they won't eat for the fear of getting close to a knife), fear of unintentionally saying something obscene, or swearing, fear of being held responsible for something terrible like fires and floods].

Compulsions are repetitive behaviors or mental acts aimed at preventing or reducing distress and/or anxiety caused by obsessions or by discomforting sensations. 4 In children, compulsions tend to occur before obsessions, ${ }^{5}$ but it is still unclear whether this is related to the cognitive immaturity of children, who would be unable to perceive and report the occurrence of an obsessive behavior, or whether childhood-onset $O C D$ differs from that observed in adults.

Some compulsions often observed in children are: cleaning or washing rituals [they may involve parts of the body or objects (sometimes these symptoms are only detected when patients present with irritation, cracking or even bleeding of the skin)]; checking behavior [checking doors, locks, stove, windows over and over; checking whether they have not hurt themselves or others; checking whether nothing terrible is about to happen; checking whether they have not made any mistakes (children get out of the bed several times to check if the house door is locked)]; symmetry and ordering behaviors [necessity to have objects in a certain place or expectation that events should follow a specific and precise order. Objects have to be symmetrically arranged or matched (children say that the way things are arranged is more important than their being arranged, because if they are not "just right," feelings of discomfort, unease or anxiety arise)]; hoarding [collecting and keeping things that are often worthless (e.g.: newspapers, magazines, candy wrappers)]; and tic-like compulsions [behaviors that are similar to tics but that are aimed at reducing anxiety, fear or worry caused by an obsession (e.g.: touching, rubbing, patting, eye blinking, or staring)]. To some extent, these compulsions strengthen the association between $O C D$ and tic disorders. 
Although most compulsions are easily detectable, mental rituals are not. These rituals are true mental "behaviors" that need to be repeated over and over [e.g.: silently counting or praying, mentally dividing words, phrases or objects, thinking a "good" thought to neutralize a "bad" thought]. Since these rituals are repetitive and inevitable, they tend to interfere substantially with a child's capacity to concentrate.

\section{Tics and TS}

Tics are sudden, rapid and repetitive vocalizations or movements performed in a nonrhythmic, stereotyped fashion without any apparent reason, usually occurring in attacks or bouts. Motor tics have been classified according to the involvement of muscle groups. Thus we have simple motor tics (e.g.: eye blinking), and complex motor tics (e.g.: hopping). Tics may be organized in a defined sequence, suggesting a combination of symptoms. They can be transient or chronic, although in chronic cases symptoms always vary with time as to their location. Vocal tics, or more appropriately, phonic tics (as many of them do not involve the vocal cords) may also be simple (sniffing, throat clearing) or complex (whistling, uttering words, repeating sentences). Tics are classified into transient (lasting less than one year), chronic motor tics and chronic vocal tics (lasting over one year), and TS when motor and vocal tics persist for over one year. Coprolalia (utterance of obscene words), which is perhaps the symptom that used to be most frequently associated with TS in the past, is not commonly observed.

Despite the peculiarities of the symptoms, tics often begin at the age of seven years as simple tics (e.g.: eye blinking, nodding one's head) and show a rostrocaudal progression. Complex vocal tics tend to appear one or two years after simple tics. Cognitively mature children report that some stimuli or sensations tend to precede tics. These stimuli are unpleasant; they are usually a weird sensation (general or located in a specific part of the body), irritation, itching, inner tension, or energy, which needs to be released. Tics relieve this sensation.

Tics tend to exacerbate in the presence of anxiety and fatigue. They may be suppressed for a given period of time, which usually causes increased discomfort, but patients do not have total control over them. Most children, after they become aware of their tics, tend to disguise them by making movements that seemingly have a defined function, such as adjusting their glasses, running their hands through their hair, or smoothing their clothes.

\section{Association between OCD and tics}

Childhood-onset OCD is more common among boys and is frequently associated with motor tics. The symptoms differ from those observed in late-onset OCD, since they occur around the second decade of life, are more frequently seen in women, and tend to respond well to treatment. ${ }^{6}$
Evidence suggests that OCD and TS have a genetic and pathophysiological etiology. Therefore, dysfunctions of the basal ganglia and cortico-striatal circuits may be common to both disorders. ${ }^{7}$

Tic-like compulsions are found in 70 to $80 \%$ of OCD and TS patients and in 20 to $40 \%$ of patients with ticrelated OCD. ${ }^{8-11}$ Moreover, distinct subjective experiences are believed to precede or accompany repetitive behaviors (compulsions or tics). ${ }^{12-14}$ Cases of OCD that are not comorbid with tics are usually characterized by thoughts, ideas or images (cognitive phenomena) and somatic feelings of anxiety (autonomic anxiety symptoms) prior to their behaviors. Cases of OCD associated with TS or with isolated TS revealed physical and/or mental sensations of discomfort (sensory phenomena) preceding their repetitive behaviors. ${ }^{14}$ These psychopathological differences have been useful to clinicians, helping them identify possible subgroups that seem to respond differently to treatments (see discussion further ahead).

Nevertheless, professionals who treat these patients on a regular basis notice that the classification of these behaviors into arbitrary categories shows our restricted capacity to understand the dynamics of the neurobiological process behind these behaviors. Thus, by admitting a continuum of symptoms that shift from the motor to the cognitive spectrum (Figure 1), we may hypothesize that different regions of the brain are affected by these behaviors.

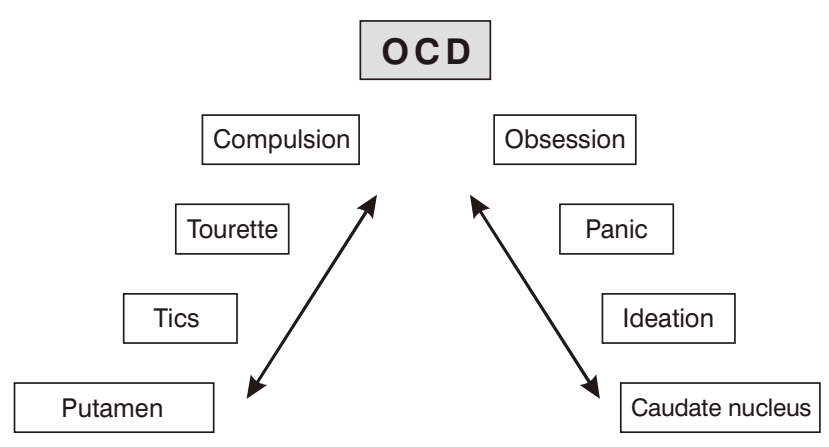

Figure 1 - Schematic model of the obsessive-compulsive disorder

Current studies have attempted to find better alternatives to clinical and psychopathological investigation. One of these alternatives has been to group obsessions and compulsions according to certain dimensions (or factors) obtained from factor and cluster analyses. 6,15,16 The following OC symptom dimensions have been consistently reproduced by factor analytic studies : "aggression obsessions/checking compulsions", "sexual, religious and somatic obsessions/checking compulsions", "symmetry obsessions and ordering compulsions", "contamination obsessions and cleaning compulsions", and "hoarding obsessions and compulsions". 
Besides helping with clinical investigation, this approach has also been useful in genetic studies. For example, Alsobrook et al. reported that when probands showed a high score for "aggressive, sexual, religious and somatic obsessions/checking compulsions" and "symmetry obsessions/ordering compulsions", their firstdegree relatives had twice the risk for OCD, tics, and TS. Mataix-Cols et al. reported that patients who present hoarding symptoms showed a worse response to psychotropic therapy.

The same procedure may be seen in the investigation of TS, in which four factors or dimensions have been proposed; aggressive phenomena (kicking, fighting, throwing temper fits), pure motor and phonic symptoms, compulsive phenomena (touching, repeating words, throat clearing), and a complex dimension that includes a wide array of behaviors. ${ }^{18}$

\section{Diagnostic criteria}

There are no biological markers for the diagnosis of OCD and TS. The available criteria are proposed by DSM-IV 4 and the International Classification of Diseases (ICD-10). ${ }^{19}$ Both DSM-IV and ICD-10 use the same diagnostic criteria for children, adolescents, and adults, but it should be underscored that it is not essential that obsessive-compulsive (OC) symptoms are exacerbated or irrational in childhood (Table 1 ). Chronic motor tic disorders differ from TS in that motor or vocal motor tic is not concomitantly observed. Transient tic disorders are diagnosed according to the length of the tics, which should be equal to or longer than one month, but shorter than one year. The current diagnosis of TS is given when the patient has multiple motor tics and, at least, one vocal tic (motor and vocal tics not necessarily occurring concomitantly), for at least one year in which tics were not absent for longer than three months in a row (Table 2).

Table 1 - DSM-IV diagnostic criteria for OCD

The person exhibits either obsessions or compulsions

The person recognizes that the obsessions or compulsions are excessive or unreasonable*

The obsessions or compulsions cause marked distress, are time consuming (take more than 1 hour a day), or significantly interfere with the person's normal routine, occupational/ academic functioning

If another axis I disorder is present, the content of the obsessions or compulsions is not restricted to it (e.g., eating disorder)

* Specify as poor insight; do not consider in children.
Table 2 - DSM-IV diagnostic criteria for Tourette syndrome

Both multiple motor and one or more vocal tics have been present at some time during the illness (not necessarily concurrently)

The tics occur many times a day (usually in bouts) nearly every day or intermittently thought out a period of more than 1 year, and during this period there was never a tic-free period of more than 3 consecutive months

The disturbance causes marked distress or significant impairment in social, occupational, or other important areas of functioning

Onset before age 18 years

The disturbance is not due to the direct physiological effects of a substance or a general medical condition (e.g., Huntington's disease)

\section{Differential diagnosis}

The difference between OCD and other anxiety disorders is of paramount importance to the improvement of a psychopathological continuum model. For instance, separation anxiety may be similar to OCD when the child is separated from his/her parents and is filled with thoughts that something bad might happen to them. Patients with panic disorder may seem obsessive with repetitive ideas that they will fall ill, or that they will develop a compulsive checking behavior in relation to their health status. In addition, OCD patients often experience episodes of intense anxiety, with true panic episodes. Children with somatic obsessions (excessive concern with illness or disease) may exhibit symptoms that can be mistaken for those of panic disorders.

There is a high comorbidity between OCD and depression ( 20 to $73 \%$ of children and adolescents). ${ }^{20,21}$ Depressive ruminations may be mistaken for obsessive thoughts, but the presence of repetitive behaviors may help distinguish between the two disorders.

Besides the prevalent ideas related to depression, another type of symptom that may cause confusion with OCD is delusional ideas. In adults, this distinction tends to be facilitated by the fact that delusional ideas are accepted as being inherent to individuals. However, in children, this difference is not always clear. When this occurs, we have a "poor insight" OCD or an OCD that is associated with the diagnosis of delusional disorder or psychotic disorder without any other specification. 4

Finally, some disorders that have been considered part of the obsessive-compulsive spectrum might hamper diagnosis. Body dysmorphic disorder (BDD), characterized by a preoccupation with a perceived defect in appearance that results in significant distress, or social or occupational harm, ${ }^{4}$ is rare in childhood. This clinical picture tends to develop in adolescence and is more prevalent in patients with TS-related OCD, ${ }^{22}$ Some of the disorders classified as impulse control disorders, such as pathological gambling, 
trichotillomania, sexual compulsions, kleptomania, "compulsive shopping" also have been included in the concept of obsessive-compulsive spectrum disorders. Trichotillomania (compulsive hair pulling) is very common in childhood. Not rarely, hair pulling is also a symptom of other disorders such as schizophrenia, mental retardation, pervasive developmental disorders, personality disorders, mood disorders, anxiety disorders, and substance abuse.

Commonly, the differential diagnosis between tics and the aforementioned disorders is not difficult, once the combined pattern, the capacity of the child to suppress movements, at least transiently, and the presence of sensations that precede the movements tend to facilitate the definition of the symptoms. Differential diagnosis should consider movement disorders, such as dystonia, myoclonus, chorea, some ataxias, dyskinesia, akathisias and stereotypies. Partial seizures can also mimic tics. ${ }^{23}$ Sometimes, it is not easy to recognize dyskinetic movements in patients who were submitted to chronic neuroleptic therapy for the treatment of tics.

The differential diagnosis between OCD and TS might be difficult sometimes, especially because of the similarity between compulsions and complex tics, whose symptoms may overlap. An alternative has been to classify repetitive movements as complex tics when children have other types of tics, but no OC symptom. Likewise, when children have other OC symptoms and no tics, the repetitive behavior could be regarded as a compulsion.

\section{Etiology and pathophysiology \\ Brain anatomy and neuroimaging}

The pathophysiology of OCD and TS has been correlated. A series of parallel circuits involving cortical and subcortical regions are believed to be responsible for the modulation of repetitive behaviors. 24 Morphological and functional neuroimaging studies suggest that the metabolic activity of the orbitofrontal cortex, of the anterior portion of the cingulate gyrus, and of the caudate nucleus is abnormal in OCD patients. ${ }^{25-}$ 33 The model used to investigate the pathophysiology of OCD reveals that basal ganglia do not filter cortical impulses properly, thus causing some change in the thalamic activity (Figure 2). Therefore, excitatory impulses originated in the thalamus reach the orbitofrontal cortex, producing a "barrier" that prevents individuals from removing certain (usually irrelevant) worries from their focus of attention. ${ }^{34}$ The role of basal ganglia in OCD can be easily understood by considering the frontal cortico-striatal- thalamic-cortical circuit as a closed electrical system. In this case, the caudate nucleus (the striatal portion of the loop) should work as a circuit breaker and interrupt the circuit every time an "overload" occurs. In children, however, this circuit breaker fails to work and does not interrupt the circuit, thus allowing for the behavior to repeat itself incessantly.

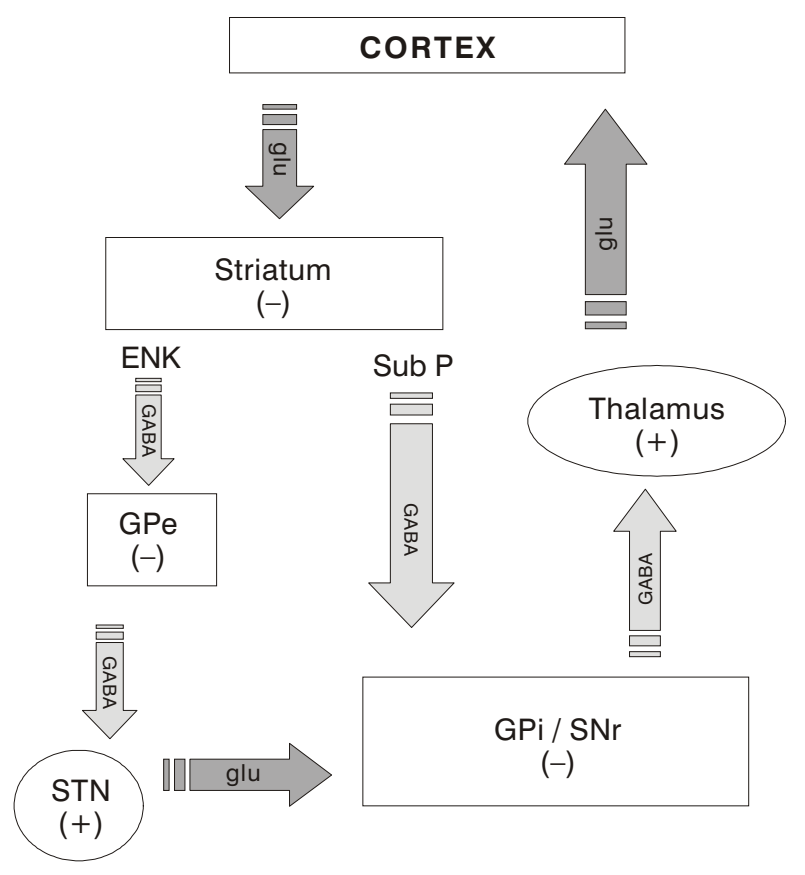

Figure 2 - Model of the cortico-striatal-thalamic-cortical circuit

Tics and TS have been described as the result of motor circuit abnormalities. This circuit consists of projections from the motor cortex, supplementary motor cortex, and somatosensorial cortex to the putamen and to the dorsolateral portion of the caudate nucleus, with a somatotropic distribution. TS patients have abnormal volumes of the caudate nucleus, putamen and globus pallidus. ${ }^{35,36} \mathrm{~A}$ hypothesis for the occurrence of tics is that the inhibitory activity of GABAergic projections from the striatum to the globus pallidus is lower in TS patients. If the corpus striatum does not inhibit the action of glutaminergic neurons found in the thalamus, excitatory projections are sent from the thalamus to the cortex. ${ }^{37}$ TS patients are considered incapable of inhibiting stimuli secondary to premonitory sensory phenomena, which results in the activation of the motor circuit and in the development of motor and phonic behaviors. 38

Animal models have given a deep insight into the pathophysiology of tics. In short, two compartments with differentiated cells (striosomes and matrisomes) are interconnected by a tonically active neuron. When the striosome compartment is more stimulated than the matrix compartment, stereotyped movements can occur (Figure 3). ${ }^{39}$ Interestingly enough, this region is more vulnerable in the prenatal and postnatal periods, and if exposed to hypoxia, it may cause an unbalance between the compartments - one of the environmental causes of TS. 40 


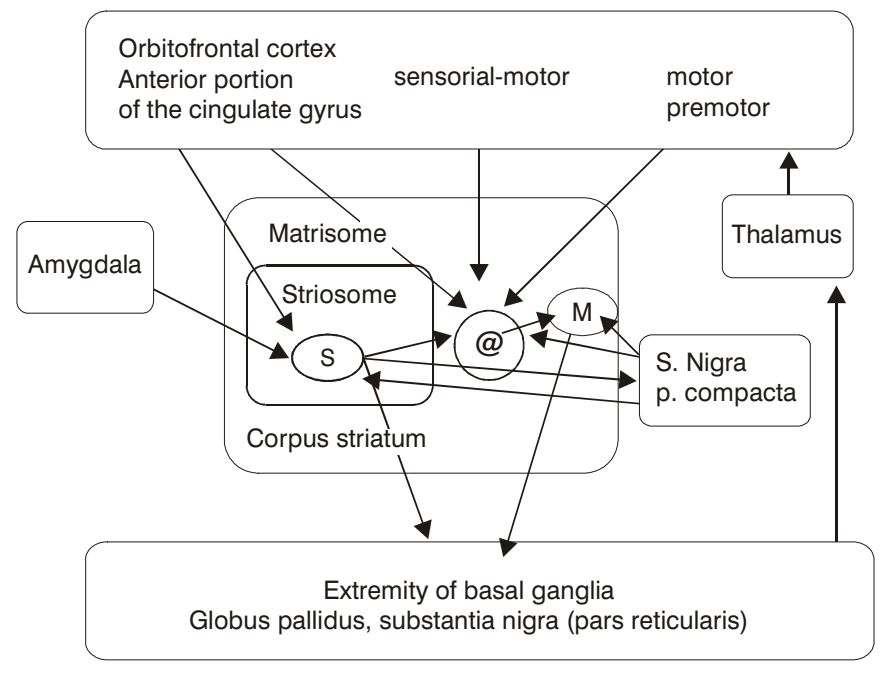

$@=$ tonically active neurons.

Figure 3 - Model of the circuit involved in the production of repetitive behaviors (adapted from Leckman \& Riddle) ${ }^{39}$

\section{Genetics}

Family studies, twin studies, and more recently, molecular studies, have emphasized the important role of genetic factors in the etiology of OCD and TS.

Recent family genetic studies have shown that OCD is a genetically heterogeneous disorder, and that the age of onset of OC symptoms is important factor to determine familial risk. It is commonly agreed that the earlier the onset of OC symptoms, the higher the risk of morbidity for OCD and OC among family members. For instance, the risk of family morbidity is at least twice as high in patients whose symptoms develop before puberty. ${ }^{41-43}$

Twin studies, reviewed by Rasmussen \& Tsuang 44 , show a concordance rate of 53 to $87 \%$ for monozygotes and of 22 to $47 \%$ for dizygotes, thus corroborating the importance of genetic factors.

To date, segregation analyses of OCD have not been able to establish the transmission model. $17,45,46$ However, Alsobrook et al. rejected the hypothesis of genetic "notransmission" when they assessed familial cases, that is, those in which more than one family member was affected with OCD. The authors conclude that the type of inheritance is complex and does not conform to a simple Mendelian pattern.

Most family studies suggest that TS is an autosomal dominant disorder with incomplete penetrance. ${ }^{47,48} \mathrm{~A}$ sibpair study of TS, conducted in the last three years by the
Tourette Syndrome Association International Consortium for Genetics, revealed two regions with lod scores higher than 2.0. The first region is located on chromosome 4 (lod score $=2.3$ ) and the second one on chromosome 8 (lod score $=2.1) .49$

The association between OCD and TS also has been pointed out by familial genetic studies. These studies have shown increased rates of OC symptoms and OCD in relatives of TS patients, $47,50-52$ in addition to an increase in tics and/or TS in relatives of OCD patients. ${ }^{53}$ In conclusion, family studies also suggest that some cases are familial and related to tics, some are familial but unrelated to tics, and some others show no family history of tics or OCD. 43

\section{Immunology}

A recent field of research in psychiatry has investigated the immune system and its influence on the central nervous system (CNS). Case reports have suggested a relationship between Sydenham's chorea, the CNS manifestation of the rheumatic fever, obsessions, and tics, since the 19th century. More recently, systematic studies have found high prevalence rates for OC symptoms and OCD in children with Sydenham's chorea. ${ }^{54-56}$

A possible subgroup of patients with OCD and/or TS, whose symptoms are triggered by the immune system, has been proposed. This group is known as PANDAS 
(Pediatric Autoimmune Neuropsychiatric Disorders Associated with Streptococcal infections). ${ }^{57}$ In an attempt to check whether this group could represent a new nosographic category, the following diagnostic criteria have been proposed: presence of OCD and/or TS, sudden prepubertal symptom onset, followed by a course with dramatic exacerbations and remissions, documented association with streptococcal infection prior to the development of symptoms and presence of motor disorders, such as choreiform movements.

It is believed that a subtype of immunological OCD does exist, which would account for approximately $10 \%$ of the cases. The model, similar to the one proposed for Sydenham's chorea, considers that the antibodies produced to bind streptococcal antigens cross react with individual's own antigens (in this case, basal ganglia molecules). The presence of these autoantibodies in the corpus striatum disrupts the cortico-striatal-cortical circuit, triggering the symptoms. Some improvement has been made in this field, but many questions still remain unanswered. The following five criteria are necessary so that an autoimmune etiology can be established: (1) presence of autoantibodies in the plasma and/or cerebrospinal fluid of patients, (2) therapeutic benefit from the removal of these autoantibodies, (3) injection of autoantibodies in experimental animals reproducing the clinical symptoms of the disease under study, (4) autoantibodies should be found at the site of the disease, (5) induction of clinical course by sensitization of experimental animals with the antigen responsible for the production of autoantibodies. 58

A series of studies has been concerned with the presence of autoantibodies in the plasma and/or cerebrospinal fluid of patients. $56,59-64$ Results suggest that we are probably dealing with a quite nonspecific IgM autoantibody. The second criterion (removal of autoantibodies) was demonstrated by only one controlled double-blind study, however, its surprising result with control of symptoms for one year has engendered researchers' enthusiasm for the immunological hypothesis. ${ }^{65}$ Two studies were made on the third criterion. ${ }^{66,67}$ A report of preliminary data suggests that the fifth criterion may be achieved soon. ${ }^{68}$ A study carried out in our setting has sought to check the induction of grooming behavior in rats by the intraperitoneal infusion of lipopolysaccharides, but the results are yet inconclusive. ${ }^{69}$ For obvious reasons, the investigation of autoantibodies at the site of the disease was not carried out. Nevertheless, a study conducted by Yale University showed autoantibodies of TS patients in the brain tissue of rats that received serum infusion from these patients in the ventrolateral region of the striatum, and also revealed that these rats had shown orofacial stereotypies after serum infusion (personal communication Mercadante MT, 2001).

Recently, this hypothesis has gained strong support. A group of researchers managed to immortalize the $B$ cell of a patient with Sydenham's chorea and produce an IgM antibody. These monoclonal antibodies recognized an antigenic portion of the $M$ protein (glucosamine). After that, it was found out that these antibodies also recognized lysogangliosides, a human antigen expressed in the CNS. Moreover, this antibody was believed to activate intracellular signaling elements. ${ }^{70}$ On the basis of these studies, it is tempting to consider that autoantibodies could be reacting with elements expressed in the neuronal membranes of striatal regions, dysfunctionally activating some circuits that could trigger repetitive behaviors. ${ }^{71}$

Despite these pieces of evidence, it is still too soon to attribute an autoimmune etiology to some cases of OCD and TS. This line of research is of unarguably heuristic value and has prompted new therapeutic proposals based on the immune response; ${ }^{73}$ however, it has not always yielded positive results.

\section{Treatment}

Children with OCD and/or TS will have to live with these symptoms during their growth. Treating these patients consists mainly in offering them the best possible development. Therapeutic planning should take into account the effect of symptoms on the child's development, family support, and interference with learning abilities. For instance, mild cases may benefit more from medical guidance than from drug therapy. Anyway, parents and patients must be informed at the very beginning about the clinical course of the disease, its etiology, prognosis, etc.

The psychotropic approach to OCD has consisted of serotonin reuptake inhibitors (SRI). ${ }^{74}$ The drugs approved by FDA (Food Drug and Administration) to be used in children are clomipramine, fluvoxamine, sertraline and fluoxetine. In case of clomipramine, as with all tricyclic agents, heart parameters must be closely monitored. Drug interactions should be taken into consideration, due to the effects of these drugs on cytochrome P450. In children, the regular use of antibiotics may alter the serum levels of SRI. When OCD is comorbid with tic disorders or when there is an inappropriate response to SRI, the use of neuroleptics should be considered. ${ }^{75}$

Follow-up can be facilitated using symptom scales, such as the Yale-Brown Obsessive-Compulsive Scale ( $\mathrm{Y}$ BOCS) $)^{76}$ and the Children Yale-Brown ObsessiveCompulsive Scale (CY-BOCS). ${ }^{77}$

Alpha-adrenergic agonists and neuroleptics have been used to treat TS. Neuroleptics are more efficient in controlling tics. Haloperidol has been approved by the FDA for the treatment of TS. Pimozide has been approved by FDA only to treat refractory cases. Recently, risperidone has shown good preliminary results. Extrapyramidal effects, especially tardive dyskinesia, are the major drawbacks of this approach. On top of that, the effect of these drugs on the child's capacity to concentrate, possibly resulting in low school performance, is arguable. 
Alpha-adrenergic agonists have yielded positive results in controlled studies. ${ }^{78}$ The dose must be fractionated in order to reduce drowsiness, the major side effect of these drugs. Guanfacine, a more selective alpha-2 receptor agonist, has also proved efficacious in the treatment of TS, especially when there is comorbidity with attention deficit hyperactivity disorder. The advantage of this drug over clonidine is that it causes fewer side effects.

Other drugs, especially regarding refractory cases, have been employed: nicotine, tetrabenazine, benzodiazepines, and flutamide. When a muscle group can be identified, botulinum toxin injection is a good therapeutic modality.

In addition to drug therapy, cognitive-behavioral therapy has proved to be efficacious. Cognitive distortions of OCD reveal an exaggerated assessment of risks, of intrusive thoughts and/or an excessive preoccupation with thought control and eventually an exacerbated personal responsibility. ${ }^{79}$

\section{Conclusion}

There was some great improvement in the last decade in understanding the neurobiological factors related to repetitive behaviors. This improvement has accompanied the development of neurosciences, which broaden our possibilities of exploring the genetic and molecular aspects of the CNS and its functioning. To assure this continued progress it is necessary that we identify more homogeneous subgroups of patients. With such subgroups, it will be possible to determine reliable endophenotypes that will allow exploring the familial transmission of specific patterns. These traits will allow us to determine the genes involved in the pathogenesis of obsessive-compulsive disorders and tic disorders. The following step would be the development of animal models and proteomic analysis, which could offer better and more efficacious therapeutic possibilities.

\section{Acknowledgments}

Our thanks to MackPesquisa for partially supporting the research conducted by Dr. Mercadante; and to the Obsessive Compulsive Foundation and Tourette Syndrome Association for lending their support to $\mathrm{Dr}$. Maria Conceição do Rosario-Campos.

\section{References}

1. Evans DW, Leckman JF, Carter A, Reznick JS, Henshaw D, King RA, et al. Ritual, habit and perfectionism: the prevalence and development of compulsive-like behavior in normal young children. Child Dev. 1997;68:58-68.

2. Zohar AH. The epidemiology of obsessive-compulsive disorder in children and adolescents. Child Adolesc Psychiatric Clin N Am. $1999 ; 8(3): 445-60$.

3. Zohar AH, Ratzoni G, Pauls DL, Apter A, Bleich A, Kron S, et al. An epidemiological study of obsessive-compulsive disorder and related disorders in Israeli adolescents. J Am Acad Child Adolesc Psychiatry. 1992;31(6):1057-61.
4. American Psychiatric Association. Diagnostic and Statistical Manual of Mental Disorders, DSM-IV. 4th ed. Washington, DC: American Psychiatric Press; 1994. 886p.

5. Rosario-Campos MC. Transtorno obsessivo-compulsivo de início precoce e de início tardio: características clínicas, psicopatológicas e de comorbidade [dissertação]. Faculdade de Medicina da Universidade de São Paulo: São Paulo; 1998. 99p.

6. Leckman JF, Grice DE, Boardman J, Zhang H, Vitale A, Bondi C, et al. Symptoms of obsessive-compulsive disorder. Am J Psychiatry. 1997;154:911-17.

7. Graybiel AM, Rauch SL. Toward a neurobiology of obsessivecompulsive disorder. Neuron. 2000;28:343-7.

8. George MS, Trimble MR, Ring HA, Sallee FR, Robertson MM. Obsessions in obsessive-compulsive disorder with and without Gilles de la Tourette's syndrome. Am J Psychiatry. 1993;105(1): 93-7.

9. Holzer JC, Goodman WK, McDougle CJ, Baer L, Boyarsky BK, Leckman JF, et al. Obsessive-compulsive disorder with and without a chronic tic disorder: a comparison of symptoms in 70 patients. Br J Psychiatry. 1994;164:469-73.

10. Leckman JF, Cohen DJ. Tic disorders. In: Rutter M, Taylor E, Hersov L. Child and Adolescent Psychiatry - Modern Approaches. 3rd ed. London: Blackwell Scientific Publications; 1994. p. 455-466.

11. Leckman JF, Grice DE, Barr LC, de Vries AL, Martin C, Cohen DJ, et al. Tic-related vs. non-tic-related obsessive-compulsive disorder. Anxiety. 1995;1:208-15.

12. Miguel EC, Coffey BJ, Baer L, Savage CR, Rauch SL, Jenike MA. Phenomenology of intentional repetitive behaviors in obsessivecompulsive disorder and Tourette's syndrome. J Clin Psychiatry. 1995; 56:246-55.

13. Miguel EC, Baer L, Coffey BJ, Rauch SL, Savage CR, O'Sullivan $\mathrm{RL}$, et al. Phenomenological differences appearing with repetitive behaviours in obsessive-compulsive disorder and Gilles de la Tourette syndrome. Br J Psychiatry. 1997;170:140-5.

14. Miguel EC, do Rosario-Campos MC, Prado HS, do Valle R, Rauch $\mathrm{SL}$, Coffey BJ, et al. Sensory phenomena in patients with obsessive-compulsive disorder (OCD) and/or Gilles de la Tourette syndrome (TS). J Clin Psychiatry. 2000;61:150-6.

15. Baer L. Factor analysis of subtypes of symptoms of obsessivecompulsive disorder and relation to personality and tic disorder. J Clin Psychiatry. 1994;55:18-23.

16. Mataix-Cols D, Rauch SL, Manzo PA, Jenike MA, Baer L. Use of factor-analyzed symptom dimensions to predict outcome with serotonin reuptake inhibitors and placebo in the treatment of Obsessive-Compulsive Disorder. Am J Psychiatry. 1999;156: 1409-16.

17. Alsobrook II JP, Leckman JF, Goodman WK, Rasmussen SA, Pauls DL. Segregation analysis of obsessive-compulsive disorder using symptom-based factor scores. Am J Med Gen. 1999;88:669-75.

18. Alsobrook II JP, Pauls DL. A factor analysis of tic symptoms in Gilles de la Tourette's syndrome. Am J Psychiatry. 2002;159(2):291-6.

19. World Health Organization: The ICD-10 Classification of Mental and Behavioural Disorders: Clinical Descriptions and Diagnostic Guidelines. World Organization. Geneva, 1992.

20. Flament MF, Koby E, Rapoport JL. Childhood ObsessiveCompulsive Disorder: a prospective follow up study. J Child Psychol Psychiatry. 1990;31:363-80.

21. Geller D, Biederman J, Jones J, Park K, Schwartz S, Shapiro S, et al. Is juvenile obsessive-compulsive disorder a developmental subtype of the disorder? A review of the pediatric literature. J Am Acad Child Adolesc Psychiatry. 1998;37(4):420-7.

22. Coffey BJ, Miguel EC, Biederman J, Baer L, Rauch SL, O'Sullivan $\mathrm{RL}$, et al. Tourette's disorder with and without ObsessiveCompulsive Disorder: are they different? J Nerv Ment Dis. 1998;186(4):201-6.

23. Towbin KE, Bradley PS, Cohen DJ, Leckman JF. Differential diagnosis. In: Tourette's Syndrome: tics, obsessions, compulsions, developmental psychopathology and clinical care. Leckman JF, Cohen DJ, editors. New York: Wiley \& Sons; 1999. p. $118-139$

24. Sheppard DM, Bradshaw JL, Purcell R, Pantelis C. Tourette's and comorbid syndromes: obsessive compulsive and attention deficit hyperactivity disorder. A common etiology? Clin Psychol Rev. $1999 ; 19(5): 531-52$

25. Baxter LR Jr, Schwartz JM, Mazziotta JC, Phelps ME, Pahl JJ, Guze $\mathrm{BH}$, et al. Cerebral glucose metabolic rates in nondepressed patients with obsessive-compulsive disorder. Am J Psychiatry. 1988;145:1560-3. 
26. Jenike MA, Breiter HC, Baer L, Kennedy DN, Savage CR, Olivares $M J$, et al. Cerebral structural abnormalities in obsessivecompulsive disorder: a quantitative morphometric magnetic resonance imaging study. Arch Gen Psychiatry. 1996;53:625-32.

27. Machlin SR, Harris GJ, Pearlson GD, Hoehn-Saric R, Jeffery P, Camargo EE. Elevated medial-frontal cerebral blood flow in obsessive-compulsive patients: a SPECT study. Am J Psychiatry. 1991;148:1240-2.

28. Martinot JL, Allilaire JF, Mazoyer BM, Hantouche E, Huret JD, Legaut-Demare $F$, et al. Obsessive-compulsive disorder: $a$ clinical, neuropsychological and positron emission tomography study. Acta Psychiatr Scand. 1990;82:233-42.

29. McGuire PK, Bench CJ, Frith CD, Marks IM, Frackowiak RS, Dolan RJ. Functional anatomy of obsessive-compulsive phenomena. Br J Psychiatry. 1994;164:459-68.

30. Nordahl TE, Benkelfat C, Semple WE, Gross M, King AC, Cohen RM. Cerebral glucose metabolic rates in obsessive compulsive disorder. Neuropsychopharmacol. 1989;2:23-8.

31. Rauch SL, Jenike MA, Alpert NM, Baer L, Breiter HC, Savage CR, et al. Regional cerebral blood flow measured during symptom provocation in obsessive-compulsive disorder using oxygen 15labeled carbon dioxide and positron emission tomography. Arch Gen Psychiatry. 1994;51:62-70.

32. Rubin RT, Villanueva-Meyer J, Ananth J, Trajmar PG, Mena I. Regional xenon 133 cerebral blood flow and cerebral technetium $99 \mathrm{~m}$-HMPAO uptake in unmedicated patients with obsessivecompulsive disorder and matched normal control subjects. Determination by high-resolution single-photon emission computed tomography. Arch Gen Psychiatry. 1992;49:695-702.

33. Sawle GV, Hymas NF, Lees AJ, Frackowiak RS. Obsessional slowness: functional studies with positron emission tomography. Brain. 1991;114:2191-202.

34. Baxter LR Jr, Schwartz JM, Bergman KS, Szuba MP, Guze BH, Mazziotta JC, et al. Caudate glucose metabolic rate changes with both drug and behaviour therapy for obsessive-compulsive disorder. Arch Gen Psychiatry. 1992;49:681-9

35. Peterson B, Riddle MA, Cohen DJ, Katz LD, Smith JC, Hardin MT, et al. Reduced basal ganglia volumes in Tourette's syndrome using three-dimensional reconstruction techniques from magnetic resonance images. Neurology. 1993;43:941-9.

36. Singer HS, Reiss AL, Brown JE, Aylward EH, Shih B, Chee E, et al. Volumetric MRI changes in basal ganglia of children with Tourette's syndrome. Neurology. 1993;43:950-6.

37. Peterson BS, Leckman JF, Arnsten A, Anderson GM, Staib LH, Gore JC, et al. Neuroanatomical circuitry. In: Leckman JF, Cohen DJ, editors. Tourette's syndrome: tics, obsessions, compulsions, developmental psychopathology and clinical care. New York: Wiley \& Sons; 1999. p. 230-260.

38. Leckman JF, Cohen DJ. Causes and determinants. In: Leckman JF, Cohen DJ, editors. Tourette's syndrome: tics, obsessions, compulsions, developmental psychopathology and clinical care. New York: Wiley \& Sons; 1999. p. 155-175.

39. Leckman JF, Riddle MA. Tourette's syndrome: when habitforming systems form habits of their own? Neuron. $2000 ; 28(2): 349-54$.

40. Leckman JF, Herman AE. Maternal behavior and developmental psychopathology. Biol Psychiatry. 2002;51(1):27-43.

41. Bellodi L, Sciuto G, Diaferia G, Ronchi P, Smeraldi E. Psychiatric disorders in the families of patients with obsessive-compulsive disorder. Psychiatry Res. 1992;42:111-20.

42. Nestadt G, Samuels J, Riddle M, Bienvenu JO, Liang KY, LaBuda $M$, et al. A family study of obsessive-compulsive disorder. Arch Gen Psychiatry. 2000;57:358-63.

43. Pauls DL, Alsobrook JP 2nd, Goodman W, Rasmussen S, Leckman JF. A family study of obsessive-compulsive disorder. Am J Psychiatry. 1995;152:76-84.

44. Rasmussen SA, Tsuang MT. Clinical characteristics and family history in DSM-III obsessive-compulsive disorder. Am J Psychiatry. 1986;143:317-22.

45. Cavallini MC, Pasquale L, Bellodi L, Smeraldi E. Complex segregation analysis for obsessive-compulsive disorder and related disorders. Am J Med Genet. 1999;88:38-43.

46. Nicolini H, Hanna G, Baxter L, Schwartz J, Weissbacker K, Spence MA. Segregation analysis of obsessive compulsive and associated disorders. Preliminary results. Ursus Med. 1991;1: 25-8.

47. Eapen V, Pauls DL, Robertson MM. Evidence for autosomal dominant transmission in Tourette's syndrome - United Kingdom cohort study. Br J Psychiatry. 1993;162:593-6.
48. Pauls DL, Raymond $\mathrm{CL}$, Stevenson JM, Leckman JF. A family study of Gilles de la Tourette syndrome. Am J Hum Genet. 1991;48:154-63.

49. Tourette Syndrome Association International consortium for genetics. A complete genome screen in sib pairs affected by Gilles de la Tourette syndrome. Am J Hum Genet. 1999;65: 1428-36.

50. Pauls DL, Towbin KE, Leckman JF, Zahner GE, Cohen DJ. Gilles de la Tourette's Syndrome and Obsessive-Compulsive Disorder - evidence supporting a genetic relationship. Arch Gen Psychiatry. 1986;43:1180-2.

51. Pauls DL, Leckman JF. The inheritance of Gilles de la Tourette's syndrome and associated behaviors: evidence for autosomal dominant transmission. N Engl J Med. 1986;315:993-7.

52. Robertson MM, Trimble MR, Lees AJ. The Psychopathology of the Gilles de la Tourette syndrome - A phenomenological analysis. Br J Psychiatry. 1988;152:383-90.

53. Leonard HL, Lenane MC, Swedo SE, Rettew DC, Gershon ES, Rapoport JL. Tics and Tourette's disorder: a 2-to 7-year followup of 54 obsessive-compulsive children. Am J Psychiatry. 1992; 149:1244-51.

54. Asbahr FR, Negrao AB, Gentil V, Zanetta DM, da Paz JA, Marques-Dias $M J$, et al. Obsessive-compulsive and related symptoms in children and adolescents with rheumatic fever with and without chorea: a prospective 6-month study. Am J Psychiatry. 1998,155(8):1122-4.

55. Mercadante MT, Busatto GF, Lombroso PJ, Prado L, RosarioCampos MC, do Valle $R$, et al. The psychiatric symptoms of rheumatic fever. Am J Psychiatry. 2000;157:2036-8.

56. Swedo SE, Rapoport JL. Phenomenology and differential diagnosis of obsessive-compulsive disorder in children and adolescents. In: Rapoport JL, editor. Obsessive-Compulsive Disorder in Children and Adolescent. Washington, DC: American Psychiatric Press; 1989. 355p.

57. Swedo SE, Leonard HL, Garvey M, Mittleman B, Allen AJ, Perlmutter $S$, et al. Pediatric autoimmune neuropsychiatric disorders associated with streptococcal infections: clinical description of the first 50 cases. Am J Psychiatry. 1998;155(2): 264-71.

58. Archelos JJ, Hartung HP. Pathogenetic autoantibodies in neurological diseases. Trends Neurosci. 2000;23(7):317-27.

59. Kiessling LS, Marcotte AC, Culpepper L. Antitelencephalic antibodies in movement disorders. Pediatrics. 1993;92:39-43.

60. Kiessling LS, Marcotte AC, Culpepper L. Antitelencephalic antibodies: tics and obsessive-compulsive symptoms. J Dev Behav Pediatr. 1994;15:421-42.

61. Morshed SA, Parveen S, Leckman JF, Mercadante MT, Bittencourt Kiss $\mathrm{MH}$, Miguel EC, et al. Antibodies against striatal, nuclear, cytoskeletal and streptoccal epitopes in children and adults with Tourette's Syndrome, Sydenham's Chorea and autoimmune disorders. Biol Psych. 2001; 50(8):566-77.

62. Singer HS, Giuliano JD, Hansen BH, Hallett JJ, Laurino JP, Benson M, et al. Antibodies against human putamen in children with Tourette Syndrome. Neurology. 1998;50:1618-24.

63. Singer HS, Giuliano JD, Hansen BH, Hallett JJ, Laurino JP, Benson $M$, et al. Antibodies against a neuron-like (HTB-10 neuroblastoma) cell in children with Tourette syndrome. Biol Psychiatry. 1999;46:775-80.

64. Swedo SE, Leonard HL, Schapiro MB, Casey BJ, Mannheim GB, Lenane MC, et al. Sydenham's chorea: Physical and psychological symptoms of St. Vitu's dance. Pediatrics. 1993;91(4):706-13.

65. Perlmutter S], Leitman SF, Garvey MA, Hamburger S, Feldman E, Leonard $\mathrm{HL}$, et al. Therapeutic plasma exchange and intravenous immunoglobulin for obsessive-compulsive disorder and tics disorders in childhood. Lancet. 1999;354:1153-8.

66. Hallett JJ, Harling-Berg CJ, Knopf PM, Stopa EG, Kiessling LS. Anti-striatal antibodies in Tourette syndrome cause neuronal dysfunction. J Neuroimmunol. 2000;111(1-2):195-202.

67. Taylor JR, Moshed SA, Parveen S, Mercadante MT, Scahill L, Peterson BS, et al. Animal model of Tourette's syndrome. Am J Psychiatry. 2002;159(4):657-60.

68. Hoffman KL, Lipkin WI. Murine model of autoimmune neuropsychiatric disorders. Proceeding of the $30^{\text {th }}$ Annual meeting of the Society for Neuroscience, November 4-9, New Orleans, Louisiana. Society for Neuroscience; 2000.

69. Luongo J. Indução de grooming pela infusão intraperitonial de lipopolissacarídeo em ratos [dissertação]. São Paulo: Universidade Presbiteriana Mackenzie; 2003.

70. Kirvan CA, Swedo SE, Heuser JS, Cunningham MW. Mimicry and autoantibody-mediated neuronal cell signaling in Sydenham chorea. Nat Med. 2003;9(7):914-20. 
71. Mercadante MT. Transtorno obsessivo-compulsivo: aspectos neuroimunológicos: existiriam evidências suficientes para a proposição de um subtipo imunológico? Rev Bras Psiquiatr. 2001;23(SII):31-4.

72. Garvey MA, Perlmutter SJ, Allen AJ, Hamburger S, Lougee L, Leonard $\mathrm{HL}$, et al. A pilot study of penicillin prophylaxis for neuropsychiatric exacerbations triggered by streptococcal infections. Biol Psychiatry. 1999;45:1564-71.

73. Walkup J. PANDAS and PITANDS. Medical Letter. Tourette Syndrome Association. 1998;1:1-4.

74. Mercadante MT, Miguel EC, Gentil V. Abordagem farmacológica do transtorno obsessivo-compulsivo. In: Miguel EC. Transtornos do Espectro Obsessivo-Compulsivo. Diagnóstico e Tratamento. Rio de Janeiro: Guanabara Koogan; 1996. p. 86-97.

75. McDougle CJ, Goodman WK, Rassmusen SA. Tic-related vs nontic-related obsessive-compulsive disorder. Anxiety. 1994/ 1995;1:208-215.

76. Goodman WK, Price LH, Rasmussen SA, Mazure C, Fleischmann $\mathrm{RL}$, Hill $\mathrm{CL}$, et al. The Yale-Brown obsessive compulsive scale: I. Development use and reliability. Arch Gen Psychiatry. 1989;46:1006-11.
77. Scahill L, Riddle MA, McSwiggin-Hardin M, Ort SI, King RA, Goodman WK, et al. Children's Yale-Brown Obsessive Compulsive Scale: reliability and validity. J Am Acad Child Adolesc Psychiatry. 1997;36:844-52.

78. Carter LL, Leckman JF, Scahill L, McDougle CJ. Pharmacological and other somatic approaches to treatment. In: Leckman JF, Cohen DJ, editors. Tourette's Syndrome: tics, obsessions, compulsions, developmental psychopathology and clinical care. New York: Wiley \& Sons; 1999. p. 370-398.

79. Torres AR. Aspectos cognitivos do transtorno obsessivocompulsivo. J Bras Psiquiatr. 1998;47(8):401-8.

Corresponding author:

Marcos Mercadante

Rua Baltazar Veiga, 24

CEP 04510-000 - São Paulo, SP, Brazil

E-mail: mt.mercadante@uol.com.br 